\title{
An unusual case of visual perseveration
}

\author{
P G CLELAND, M SA UNDERS, AND R ROSSER \\ From the Department of Neurology, Middlesbrough General Hospital, Middlesbrough, Cleveland, UK
}

SUMMARY A patient is described with an unusual type of visual perseveration caused by a right parietal infarct. The mechanism of visual perseveration is discussed with particular reference to the increased movement of the perseverated image which our patient described.

Visual perseverution is the persistence or recurrence of a visual image after removal of the visual object. In this paper we report a patient with an unusual type of this condition in which there appeared an accelerated movement of the perseverated image.

\section{Case report}

The patient, a 66-year-old housewife, was admitted to hospital in May 1979. She had suffered from migraine attacks for sixteen years. These consisted of flashes of light, usually in the left field of vision, followed by a headache, and could be aborted by taking two tablets of paracetamol. The attacks occurred several times a week and were related to stress. In May 1979 she woke up one morning with weakness of the left arm and a feeling that the arm did not belong to her. At the same time she noticed the left field of vision was misty and over the next few days experienced three episodes of visual perseveration. On the first occasion a man walked in front of her window and she continued to see him in her left field of vision but his walking was speeded up. She described the sensation as though she was watching a film being shown at the wrong speed, that speed being about twice normal. The amplitude of the movements was unchanged. On the second occasion she continued to see a child waving but, as on the previous occasion, the action was speeded up. On the third occasion, her brother put his hand through his hair. She continued to see him repeatedly perform this action at a faster rate. Each episode of perseveration lasted about ten minutes with the image gradually fading although there was no diminution of the movement. She was unable to remember whether the image was superimposed on the real world and whether it was in colour.

General examination was normal and she was a

Address for reprint requests: Dr PG Cleland, Department of Neurology Newcastle General Hospital, Newcastle upon Tyne NE4 6BE, UK Accepted 23 December 1980 sensible and articulate woman. The only abnormalities in the nervous system were a left inferior quadrantic homonomous hemianopia, left sensory inattention involving arm and leg, and impaired joint position sense in the left arm. Routine blood tests were normal. The EEG showed a right temporal abnormality while the CT scan (figure) showed a wedge shaped lesion in the

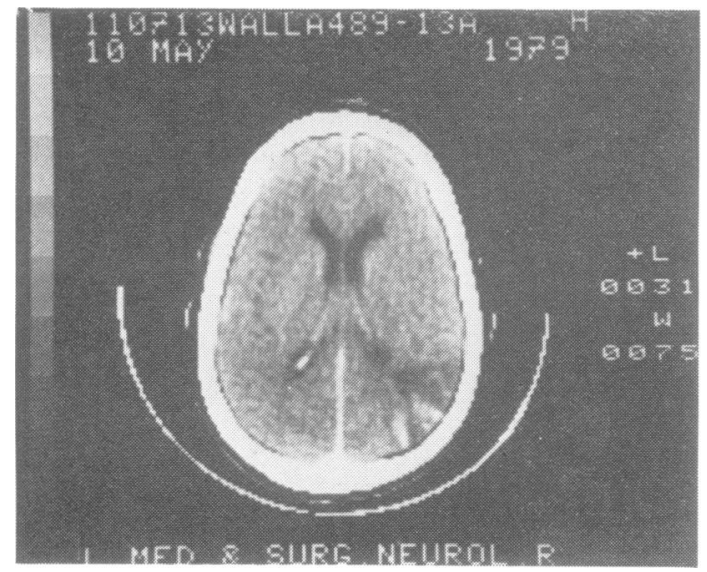

Figure CT scan showing a wedge shaped lesion in the right posterior parietal region.

right posterior parietal region, typical of infarction. A repeat scan two months later showed a decrease in the size of the lesion. A formal psychological assessment was completed in September 1979. On the Wechsler Adult Intelligence Scale her scores were as follows: verbal IQ 118, performance IQ 85, fullscale IQ 104. The age related sub-test scores are shown in the table. The overall pattern of findings suggested specific deficits in visuo-spatial and visuo-constructive abilities. The scores on the Wechsler Memory Scale are also shown in the table. Most of these results were commensurate with the IQ level with the exception of the visual reproduction score which showed a marked impairment of immediate memory for drawing 
Table Details of psychological testing

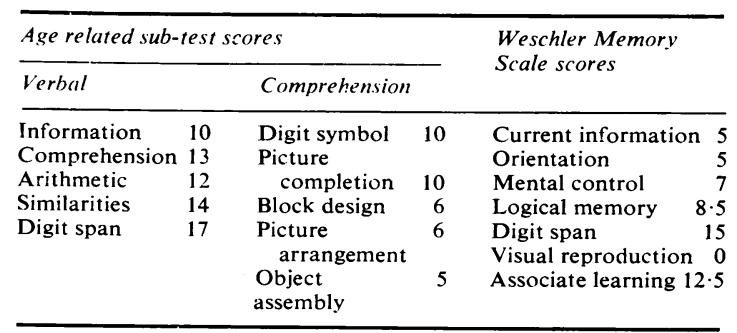

geometric figures. This impairment was confirmed by scores on the Benton Visual Retention Test (number correct 2, error score 12). Further evidence of impairment of visuo-spatial relationships and visuoconstructive ability were seen on drawings of threedimensional cubes and on constructions of a four point star with matchsticks.

\section{Discussion}

Visual perseveration is a rare but well described phenomenon occurring with parieto-occipital lesions as a result of infarction, ${ }^{1}$ tumour, ${ }^{2}$ migraine, ${ }^{3}$ trauma, ${ }^{4}$ and as part of an epileptic aura. ${ }^{5}$ It is usually an intermittent occurrence but patients have been described with perseveration lasting several weeks. Critchley ${ }^{2}$ described two types of this condition; in the first there was no distortion of the visual image while in the second the image appeared to spread over a larger area. He called the latter illusory visual spread. Our patient represents a third type of visual perseveration with apparent acceleration of movement. We are not aware of any reports of patients with a similar disorder.

The mechanism of visual perseveration is not fully understood. It bears a resemblance to retinal after images. If one looks at a bright object and then at a bland background the after image persists for about twenty seconds. It is positive against a dark background, negative against a light background, may be revived by blinking and appears to move in the direction of eye movements. The duration is related to the intensity and duration of exposure to the stimulus. In general the images in visual perseveration do not have these characteristics. However Kinsbourne and Warrington $^{4}$ showed that their patients with visual perseveration had prolonged retinal after images. They considered that visual perseveration resulted from pathological enhancement of the normal process of after image formation as a result of release of cortical visual systems from their normal inhibitory influences.

The mechanism of the increased movement is more difficult to understand. Visual perseveration of moving objects has been reported by Holmes, ${ }^{\text {' }}$ Robinson and Watt, ${ }^{7}$ Critchley, ${ }^{2}$ and Le Beau et al. ${ }^{8}$ Kinsbourne and Warrington ${ }^{4}$ showed that some patients with this condition continued to see the movement of a flickering light. The movement of the perseverated image was, however, the same as the stimulus image. One explanation of our patient's sensation of increased movement could be that her experience of the passage of time was altered. Ornstein ${ }^{9}$ showed that the apparent speed at which time passed was related to sensory input. When the latter was reduced time appeared to go faster. One could postulate that, as the memory reinforcing the visual perseveration becomes more fragmented, the decreasing input to consciousness would produce a sensation that the event was occurring more rapidly. It seems more likely, however, that the peculiar pattern of release of cortical visual systems in our patient was responsible for her unusual symptoms. One could draw an analogy between the "static" distortion of Critchley's patients with illusory visual spread and "dynamic" distortion in our patient.

Clearly we need to know more about the mechanism of storing of visual memory. It is to be hoped that as the CT scanner is more widely used, accurate localisation of lesions will be correlated with visual deficits to give a clearer view of these probems.

\section{References}

1 Meadows J, Munro S. Palinopsia. J Neurol Neuro surg Psychiatry 1977; 40:5-8.

2 Critchley $M$. Types of visual perseveration: palinopsia and illusory visual spread. Brain 1951; 74:267-99.

3 Klee A, Willanger R. Disturbance of visual perception in migraine. Acta Neurol Scand 1966; 42: 400-14.

4 Kinsbourne M, Warrington E. A study of visual perseveration. J Neurol Neurosurg Psychiatry $1963 ; 26: 468-75$.

5 Swash M. Visual perseveration in temporal lobe epilepsy. J Neurol Neurosurg Psychiatry 1979; 42:560-71.

6 Holmes G. A contribution to the cortical represensation of vision. Brain 1931; 54:470-79.

7 Robinson P, Watt A. Hallucinations of remembered scenes as an epileptic aura. Brain 1947; 70:440-8.

8 Le Beau T, Wolinietz E. Le Phénomène de persévération visuelle sa valeur localisatrice pur les lesions occipitales. Rev Neurol (Paris) 1958; 99: 524-32.

9 Ornstein R. Experience of Time. London: Pengiun Books Ltd, 1969. 